\title{
Effect of Urinary Incontinence on Quality of Life and Self Esteem of Postmenopausal Women
}

\author{
Hemmat Mostafa Elbana ${ }^{1}$, Amira Mohammed Salama ${ }^{1}$, Mona Mohammed Barakat ${ }^{2}$ \\ ${ }^{1}$ Obstetrics and Woman's Health Nursing, Faculty of Nursing, Benha University, Benha, Egypt \\ ${ }^{2}$ Mental and Psychiatric Health Nursing, Faculty of Nursing, Benha University, Benha, Egypt
}

Email address:

Amirasalama88@yahoo.com (A. M. Salama)

To cite this article:

Hemmat Mostafa Elbana, Amira Mohammed Salama, Mona Mohammed Barakat. Effect of Urinary Incontinence on Quality of Life and Self Esteem of Postmenopausal Women. American Journal of Nursing Science. Vol. 7, No. 5, 2018, pp. 182-191.

doi: 10.11648/j.ajns.20180705.15

Received: August 26, 2018; Accepted: September 19, 2018; Published: October 11, 2018

\begin{abstract}
Background: Urinary incontinence (UI) is the debilitating condition with impact on physical and psychological aspect of life with consequent effect on the quality of life $(\mathrm{QoL})$. Aim of the study was to determine the effect of urinary incontinence (UI) on quality of life and self esteem of postmenopausal women. A descriptive design was adopted to fulfil the aim of this study. The study was conducted at obstetric \& gynaecological outpatient clinic and Urological outpatient clinic at Benha University Hospital. A purposive sample of 75 postmenopausal women who had complain of UI attending gynaecological outpatient clinic and Urological outpatient clinic. Data were collected through three main tools Structured interviewing questionnaire sheet, Rosenberg's Self-Esteem Scale and Incontinence-related quality of life (I-QOL). The study Results showed that there were positive statistically significant correlation between total self esteem and total IncontinenceRelated Quality of Life. Also there is no significant relation between Incontinence-Related Quality of Life and items of sociodemographic characteristics (age, occupation, and source of income). While there were significant relation between Incontinence-related quality of life and (marital status, and educational level). Based on the result of this study it was concluded that UI symptoms directly affect HRQoL, which subsequently impacts negatively on self steam .The present study Recommended that continuous assessment for all QOL domains for incontinent women should be a part of the nursing care. Further research is required to improve our understanding of psychological and economic impact of this condition.
\end{abstract}

Keywords: Urinary Incontinence, Quality of Life, Self Esteem, Postmenopausal Women

\section{Introduction}

Postmenopausal women usually considered peak prevalence of urinary incontinence which diminish quality of life and disrupt daily activities. Recently, as the average life expectancy of women has increased and an increasing number of women maintain various social roles after menopause, urinary incontinence (UI) has become an important medical and social issue [1]. It is estimated that 25$45 \%$ of women of different ages have involuntary urine loss and $9-39 \%$ of women over 60 years report daily urinary leakage [2].

Urinary incontinence is a troublesome and probably underreported disorder in women. Estimated 19\% of women under the age of 45 experience UI and $29 \%$ of women over the age of 80 also experience this condition. [3] In general population, some leading factors to UI among aging people are advanced age (especially over 80 years) low physical activity, diabetes, brain stroke, delirium and urinary system infection [4].

Control of micturition is a complex physiological and anatomical process which often fails in women. According to the International Continence Society (ICS), urinary incontinence (UI) is defined as the complaint of any involuntary loss of urine that is a social or hygienic problem. Worldwide, over 200 million people are living with urinary incontinence. It is three times more common in women than men [5].

The low estrogen production in menopausal and postmenopausal women produces symptoms from the autonomic nervous system such as flushing and perspiration 
and psychiatric symptoms such as depression. Furthermore, the mucous membranes of the genitourinary tract undergo atrophy resulting in incontinence vaginitis, dyspareunia and cysto-urethritis. The reported prevalence of UI in postmenopausal women appears to be wide and varied and the reason/s for this is their anatomic, social and cultural status and also pregnancy, delivery and menopause [6].

UI has been shown to be bothersome to patients and to negatively affect many aspects of life, including sleep, emotional well-being and depression, relationships, work productivity, and overall health-related quality of life (HRQoL) [7]. Urinary symptoms may affect women routine adversely, leading to limitation in physical, social, occupational, domestic and sexual activities [8]. The social and hygienic discomfort caused by the fear of urine lost, urine smell, and the need to use hygienic protectors and clothes changes frequency may affect negatively women quality of life (QoL) [9].

Self-esteem and independence are affected by voluntary control of the bladder, which begins in childhood as something personal not socially talked about. Therefore, urine loss is a condition with a profound impact in social life, both for children and adults. [10] Urinary incontinence (UI) among women is a major health concern with physiological, psychological and economic impact [11].

Proactive management is required, as there are many cases in which the individual is ashamed of her UI and worries about it alone, rather than discussing the symptoms with experts or receiving medical help [12]. Quality of life is affected by health-related factors accompanying old age and social environmental factors; in particular, depression among elderly women reportedly exerts a negative effect on quality of life [13].

The life expectancy is increasing with the aging of population, therefore preventive measures to address health risk factors and safety issues must be directed more prominent in health services. UI, as a geriatric disorder, is objectively approved unwanted urine leak, which women are at more risk than men, because of their anatomic, social and cultural status and also pregnancy, delivery and menopause [14].

A nurse approach to patients with UI can help them express their fears, worries, and embarrassment. Let patients know that they are not alone and that UI isn't something they have to live with. Provide education about protective products, pelvic floor muscle training exercises, behaviour modification, and symptom management. Encourage them to learn more about their condition. Reducing UI symptoms decreases stress and embarrassment, allowing patients to participate in family and social activities [15].

Significance of the study:

Although UI is not a life-threatening condition, it has an impact on health, resulting in a higher predisposition to stress. European, North-American and Brazilian studies demonstrated important stress scores in women with UI, in different age groups. Social discomfort comes from the fear of urinary loss, the smell, the need to use absorbent pads and to change clothes frequently, predisposing the woman to a high level of stress. Irrelative symptoms (nocturia and urinary urgency) also disrupt sleep, leading to fatigue, stress and depression. [16] Having a UI may have several adverse effects on a person's social life since women limit social activities due to the possible shame and fear associated with leaving the house. [17]

Aim of the study

This study aimed to determine the effect of urinary incontinence (UI) on quality of life and self esteem of postmenopausal women.

\section{Materials and Method}

\subsection{Research Design}

Descriptive design was utilized to fulfill the aim of this study.

\subsection{Setting}

The study was conducted at obstetric \& gynecological outpatient clinic and Urological outpatient clinic at Benha University Hospital. This setting was particularly chosen because flow rate of women with urinary incontinence is satisfactory for the study.

\subsection{Subjects}

A purposive sample of 75 women who have reported amenorrhea for at least 12 months were considered on postmenopausal period among those attending gynecological outpatient clinic and Urological outpatient clinic. The studied sample was selected according to the following inclusion criteria: Women at postmenopausal period, diagnosed with urinary incontinence, can read and write, accepted to participate in the study. Exclusion criteria were diabetic nephropathy, congenital urological disorders, previous central nervous system damage, bladder cancer, urinary tract infection, conditions that may have caused neurogenic bladder diseases, and other major neurological diseases.

\subsection{Tools of Data Collection}

Three tools will be utilized for collecting data.

\subsubsection{First Tool: - Structured Interviewing Questionnaire Sheet}

It was designed by the researchers after reviewing related literature. The sheet is written in simple Arabic language in the form of close and open ended questions and consisted of three parts:

The first part: - included socio demographic questions (age, marital status, educational level, occupation, and source of income).

The second part: - included questions about obstetric history (number of pregnancy, number of delivery, method of delivery, and occurrence of abortion).

The third part: - included questions about past history 
(Duration of urinary incontinence, doctor visit in previous year, causes of urinary incontinence frequency of urinary incontinence (last month), and frequency of urinary incontinence (day).

\subsubsection{Second Tool: - Rosenberg' Self-Esteem Scale}

This instrument was adopted from [18]. It is made up of total 10 -items that measures global self-worth by measuring both positive and negative feelings about the self. Scores were calculated as follows: for items 1, 2, 4, 6, and 7: Strongly agree $=3$, Agree $=2$, Disagree $=1$, Strongly disagree $=0 \&$ For items $3,5,8,9$, and 10 (which are reversed in valence): Strongly agree $=0$, Agree $=1$, Disagree $=2$, Strongly disagree $=3$. The scale ranges from $0-30$. Scores between 15 and 25 are within normal range; scores below 15 suggest low self-esteem.

\subsubsection{Third Tool: - Incontinence-Related Quality of Life (I-QOL)}

This instrument was adopted from [19] for assessing QOL changes as a consequence of urinary incontinence. It is made up of a total of 22 questions and is divided into three subscales, consisting of eight questions for "avoidance and limiting behaviour," nine questions for "psychosocial impact," and five questions for "social embarrassment". Each question was scored on a four-point Likert scale, with answers ranging from "Extremely-4 points" to "Not at al -0 points," and with scores ranging of $0-88$, higher scores signified a higher quality of life.

\subsection{Method}

The study was executed according to the following steps:

\subsubsection{Administrative Approval}

An official permission was obtained from the hospital authorities in the identified setting to collect the necessary data, and patient consent was be obtained to participate in study.

\subsubsection{A Pilot Study}

After the development of tools, a pilot study was carried out on $10 \%$ of the studied subjects (7) postmenopausal women who were excluded from the main study sample.

The purposes of the pilot study were to:

(1) Ascertain the clarity and the applicability of the tools

(2) Ascertain the relevance and content validity of the tools.

(3) Estimate the time needed to complete the sheet.

(4) Detect any problem peculiar to the statements such as sequence and clarity that might interfere with the process of data collection. The necessary changes were undertaken.

The results of the pilot study:

After conducting the pilot study, it was found that:

(1) The tools were clear and applicable; however, few words were modified

(2) Tools were relevant and valid.
(3) No problem that interferes with the process of data collection was detected.

(4) Following this pilot study the tools were made ready for use.

\subsubsection{Validity}

Content validity was done to assure that the utilized tools measure what it was supposed to measure. Tools developed by the researchers were examined by a panel of five experts to determine whether the included items clearly and adequately cover the domain of content addressed. The percentage of consensus among experts regarding the structured interviewing questionnaire was $94 \%$ and the prepost-test was $87 \%$.

\subsubsection{Reliability}

Test-retest was repeated to the same sample of maternity nurses on two occasions and then compares the scores The Cronbach's coefficient alpha of Incontinence-Related Quality of Life is 0.93 for total Score, while Cronbach's alpha for Rosenberg' Self-Esteem Scale is 0.90 .

\subsubsection{Ethical Considerations}

(1) Approvals of women were obtained before data collection and after explaining the purpose of the study.

(2) Anonymity was assured as the filled questionnaire sheets were given a code number (not by names).

(3) The women were ensured that questionnaire sheet will be used only for the purpose of the study and will be discarded at the end of the study.

(4) The study maneuvers didn't entail any harmful effects on participation.

(5) The women who participated in the study were informed about having the right to withdraw at any time without giving any reason.

\subsubsection{Field Work}

The actual field work was carried out from the beginning of April 2017 to the end of April 2018 covering twelve months. The study setting was visited three times/week started from $9 \mathrm{Am}$ to $12 \mathrm{Pm}$. At the beginning of interview the researcher greeted the women, introduced herself to each woman, explained the purpose of the study, took oral consent to participate in the study, filled interviewing questionnaire sheet. and then each woman was asked to fill Rosenberg's Self-Esteem Scale which made up of a total of 10 statements. Subjects assign a value on a 4-point scale from 1 (Strongly disagree) to 4 (Strongly agree) for each item.

The researchers assessed QOL using the I-QOL that consists of 22 items evaluating concerns specifically relating to incontinence. Subjects assign a value on a 4-point scale from 4(extremely) to 0 (not at all) for each item. For all items, higher scores indicated better incontinence related QOL. The 22 items are divided into 3 subscales: avoidance and limiting behaviour; psychosocial impact; and social embarrassment. 


\section{Results}

Table 1. Frequency distribution of study sample regarding sociodemographic characteristics $(n=75)$.

\begin{tabular}{|c|c|c|}
\hline Socio-demographic characteristics & no & $\%$ \\
\hline \multicolumn{3}{|l|}{ Age } \\
\hline$<50$ years & 41 & 54.7 \\
\hline$\geq 50$ years & 34 & 45.3 \\
\hline Mean \pm SD & $50.6 \pm 3.5$ & \\
\hline \multicolumn{3}{|l|}{ Marital status } \\
\hline Single & 5 & 6.7 \\
\hline Married & 56 & 74.7 \\
\hline Divorced & 6 & 8.0 \\
\hline Widowed & 8 & 10.7 \\
\hline \multicolumn{3}{|l|}{ Education level } \\
\hline Illiterate & 11 & 14.7 \\
\hline Read \& write & 7 & 9.3 \\
\hline Low level & 5 & 6.7 \\
\hline Moderate & 46 & 61.3 \\
\hline High level & 6 & 8.0 \\
\hline \multicolumn{3}{|l|}{ Occupation } \\
\hline Working & 59 & 78.7 \\
\hline Not working & 11 & 14.7 \\
\hline Pension & 5 & 6.7 \\
\hline \multicolumn{3}{|l|}{ Source income } \\
\hline Self & 35 & 46.7 \\
\hline Husband & 27 & 36.0 \\
\hline Children & 9 & 12.0 \\
\hline Pension & 4 & 5.3 \\
\hline
\end{tabular}

Table 2. Frequency distribution of study sample regarding obstetric history $(n=75)$.

\begin{tabular}{lll}
\hline Obstetric history & no & \% \\
\hline Number of pregnancy & 5 & \\
Not yet & 49 & 6.7 \\
$1-3$ times & 21 & 65.3 \\
$\geq 3$ times & 5 & 28.0 \\
Number of delivery & 59 & \\
Not yet & 21 & 6.7 \\
$1-3$ times & & 65.3 \\
$\geq 3$ times & 22 & 28.0 \\
Method of delivery $(\mathrm{n}=70)$ & 48 & 31.4 \\
Cesarean section & & 68.6 \\
Normal delivery & 15 & \\
Abortion & 60 & 20.0 \\
Yes & & 80.0 \\
No & & \\
\hline
\end{tabular}

Table 1: reveals that more than half $(54 \%)$ of the sample were in the age group of $<50$ years old with mean age $50.6 \pm 3.5$ and about three quarters $(74.7 \%)$ were married. This table also shows that nearly two thirds $(61.3 \%)$ of sample had moderate education and about (78.7\%) were working women while less than half (46.7\%), their monthly income is from their self.

Table 2: Shows that more than two thirds $(65.3 \%)$ of the sample had 1-3 deliveries, also more than two thirds (68.6\%) had normal delivery. And more than three quarters'(80.0\%) had no abortion.

Table 3. Frequency distribution of study sample regarding medical history $(N=75)$.

\begin{tabular}{|c|c|c|}
\hline Medical history & no & $\%$ \\
\hline \multicolumn{3}{|c|}{ Duration of urinary incontinence } \\
\hline$<$ one year & 11 & 14.7 \\
\hline $1-<3$ years & 44 & 58.7 \\
\hline $3-<5$ years & 13 & 17.3 \\
\hline$\geq 5$ years & 7 & 9.3 \\
\hline \multicolumn{3}{|c|}{ Doctor visit in previous year } \\
\hline $0-1$ visits & 17 & 22.6 \\
\hline $2-3$ visits & 9 & 12.0 \\
\hline $4-5$ visits & 43 & 57.3 \\
\hline$\geq 6$ visits & 6 & 8.0 \\
\hline \multicolumn{3}{|c|}{ Causes of urinary incontinence } \\
\hline correct & 10 & 13.3 \\
\hline Incorrect & 65 & 86.7 \\
\hline \multicolumn{3}{|c|}{ Frequency urinary incontinence (last month) } \\
\hline No & 4 & 5.3 \\
\hline 1-2times & 4 & 5.3 \\
\hline 3-4 times & 7 & 9.3 \\
\hline$\geq 4$ times & 60 & 80.0 \\
\hline \multicolumn{3}{|c|}{ Frequency urinary incontinence (day) } \\
\hline 1-2 times & 11 & 14.7 \\
\hline 3-4 times & 50 & 66.7 \\
\hline$\geq 4$ times & 14 & 18.7 \\
\hline
\end{tabular}

Table 3: Displays that more than half of sample (58.7\%) had $1-<3$ years duration of urinary incontinence. Also $(57.3 \%)$ had $4-5$ visits to doctor. This table also reveals that the more than three quarters of sample $(80.0 \%)$ had $\geq 4$ time's frequency urinary incontinence last month, while more than two thirds (66.7\%) had 3-4 times frequency urinary incontinence per day.

Table 4. Correlation between total Self Esteem and total IncontinenceRelated Quality of Life $(N=75)$.

\begin{tabular}{lll}
\hline \multirow{2}{*}{ scales } & \multicolumn{2}{l}{ Total self esteem } \\
\cline { 2 - 3 } & $\mathbf{r}$ & p-value \\
\hline Total Incontinence-related quality of life & 0.54 & $0.05^{*}$ \\
\hline
\end{tabular}

Table 4: Represents that there were positive significant correlation between total Self Esteem and total IncontinenceRelated Quality of Life. 
Table 5. Relation between total Incontinence-related quality of life and socio-demographic characteristics.

\begin{tabular}{|c|c|c|c|c|c|c|c|c|c|c|}
\hline \multirow{3}{*}{$\begin{array}{l}\text { Socio-demographic } \\
\text { characteristics }\end{array}$} & \multicolumn{10}{|c|}{ Total Incontinence-related quality of life } \\
\hline & \multicolumn{2}{|c|}{ Extremely } & \multicolumn{2}{|c|}{ Some time } & \multicolumn{2}{|c|}{ May be } & \multicolumn{2}{|c|}{ Not at all } & \multirow[t]{2}{*}{$\mathbf{X 2}$} & \multirow[t]{2}{*}{ p-value } \\
\hline & no & $\%$ & no & $\%$ & no & $\%$ & no & $\%$ & & \\
\hline$<50$ years & 2 & 100.0 & 21 & 52.5 & 13 & 61.9 & 5 & 41.7 & \multirow{2}{*}{2.99} & \multirow{2}{*}{0.39} \\
\hline$\geq 50$ years & 0 & 0.0 & 19 & 47.5 & 8 & 38.1 & 7 & 58.3 & & \\
\hline \multicolumn{11}{|l|}{ Marital Status } \\
\hline Single & 0 & 0.0 & 4 & 10.0 & 1 & 4.8 & 0 & 0.0 & \multirow{4}{*}{21.84} & \multirow{4}{*}{$0.022 *$} \\
\hline Married & 2 & 100.0 & 24 & 60.0 & 19 & 90.5 & 11 & 91.7 & & \\
\hline Divorced & 0 & 0.0 & 4 & 10.0 & 1 & 4.8 & 1 & 8.3 & & \\
\hline Widowed & 0 & 0.0 & 8 & 20.0 & 0 & 0.0 & 0 & 0.0 & & \\
\hline \multicolumn{11}{|l|}{ Educational Level } \\
\hline Illiterate & 0 & 0.0 & 7 & 17.5 & 3 & 14.3 & 1 & 8.3 & \multirow{5}{*}{24.78} & \multirow{5}{*}{$0.035^{*}$} \\
\hline Read \& write & 1 & 50.0 & 4 & 10.0 & 1 & 4.8 & 1 & 8.3 & & \\
\hline Low level & 0 & 0.0 & 4 & 10.0 & 0 & 0.0 & 1 & 8.3 & & \\
\hline Moderate & 0 & 0.0 & 22 & 55.0 & 15 & 71.4 & 9 & 75.0 & & \\
\hline High level & 1 & 50.0 & 3 & 7.5 & 2 & 9.5 & 0 & 0.0 & & \\
\hline \multicolumn{11}{|l|}{ Occupation } \\
\hline Working & 2 & 100.0 & 30 & 75.0 & 16 & 76.2 & 11 & 91.7 & \multirow{3}{*}{15.16} & \multirow{3}{*}{0.52} \\
\hline Not working & 0 & 0.0 & 8 & 20.0 & 2 & 9.5 & 1 & 8.3 & & \\
\hline Pension & 0 & 0.0 & 2 & 5.0 & 3 & 14.3 & 0 & 0.0 & & \\
\hline \multicolumn{11}{|l|}{ Source income } \\
\hline Self & 2 & 100.0 & 17 & 42.5 & 9 & 42.9 & 7 & 58.3 & \multirow{4}{*}{8.78} & \multirow{4}{*}{0.45} \\
\hline Husband & 0 & 0.0 & 16 & 40.0 & 7 & 33.3 & 4 & 33.3 & & \\
\hline Children & 0 & 0.0 & 4 & 10.0 & 5 & 23.8 & 0 & 0.0 & & \\
\hline Pension & 0 & 0.0 & 3 & 7.5 & 0 & 0.0 & 1 & 8.3 & & \\
\hline
\end{tabular}

Table 5: Displays that there is no significant relation between Incontinence-Related Quality of Life and items of sociodemographic characteristics (age, occupation, and source of income). While there were significant relation between Incontinence-related quality of life and (marital status, and educational level).

Table 6. Relation between total self esteem and socio-demographic characteristics of the studied sample.

\begin{tabular}{|c|c|c|c|c|c|c|c|c|c|c|}
\hline \multirow{3}{*}{$\begin{array}{l}\text { Socio-demographic } \\
\text { characteristics } \\
\text { Age }\end{array}$} & \multicolumn{10}{|c|}{ Total self esteem } \\
\hline & \multicolumn{2}{|c|}{ Strongly agree } & \multicolumn{2}{|c|}{ Agree } & \multicolumn{2}{|c|}{ Disagree } & \multicolumn{2}{|c|}{ Strongly disagree } & \multirow[t]{2}{*}{$\mathbf{X 2}$} & \multirow[t]{2}{*}{ p-value } \\
\hline & no & $\%$ & no & $\%$ & no & $\%$ & no & $\%$ & & \\
\hline$<50$ years & 7 & 77.8 & 8 & 44.4 & 13 & 50.0 & 13 & 59.1 & \multirow{2}{*}{13.1} & \multirow{2}{*}{$0.039^{*}$} \\
\hline$\geq 50$ years & 2 & 22.2 & 10 & 55.6 & 13 & 50.0 & 9 & 40.9 & & \\
\hline \multicolumn{11}{|l|}{ Marital Status } \\
\hline Single & 1 & 11.1 & 0 & 0.0 & 2 & 7.7 & 2 & 9.1 & \multirow{5}{*}{17.43} & \multirow{4}{*}{$0.022 *$} \\
\hline Married & 8 & 88.9 & 14 & 77.8 & 21 & 80.8 & 13 & 59.1 & & \\
\hline Divorced & 0 & 0.0 & 3 & 16.7 & 1 & 3.8 & 2 & 9.1 & & \\
\hline Widowed & 0 & 0.0 & 1 & 5.6 & 2 & 7.7 & 5 & 22.7 & & \\
\hline \multicolumn{10}{|l|}{ Educational Level } & \\
\hline Illiterate & 0 & 0.0 & 1 & 5.6 & 6 & 23.1 & 4 & 18.2 & \multirow{5}{*}{22.04} & \multirow{5}{*}{$0.0023 * *$} \\
\hline Read \& write & 1 & 11.1 & 0 & 0.0 & 3 & 11.5 & 3 & 13.6 & & \\
\hline Low level & 1 & 11.1 & 0 & 0.0 & 2 & 7.7 & 2 & 9.1 & & \\
\hline Moderate & 7 & 77.8 & 16 & 88.9 & 11 & 42.3 & 12 & 54.5 & & \\
\hline High level & 0 & 0.0 & 1 & 5.6 & 4 & 15.4 & 1 & 4.5 & & \\
\hline \multicolumn{11}{|l|}{ Occupation } \\
\hline Working & 7 & 77.8 & 17 & 94.4 & 16 & 61.5 & 19 & 86.4 & \multirow{3}{*}{24.34} & \multirow{3}{*}{$0.022 *$} \\
\hline Not working & 2 & 22.2 & 1 & 5.6 & 8 & 30.8 & 0 & 0.0 & & \\
\hline Pension & 0 & 0.0 & 0 & 0.0 & 2 & 7.7 & 3 & 13.6 & & \\
\hline \multicolumn{11}{|l|}{ Source income } \\
\hline Self & 5 & 55.6 & 6 & 33.3 & 11 & 42.3 & 13 & 59.1 & \multirow{4}{*}{19.12} & \multirow{4}{*}{$0.02 *$} \\
\hline Husband & 4 & 44.4 & 11 & 61.1 & 9 & 34.6 & 3 & 13.6 & & \\
\hline Children & 0 & 0.0 & 0 & 0.0 & 3 & 11.5 & 6 & 27.3 & & \\
\hline Pension & 0 & 0.0 & 1 & 5.6 & 3 & 11.5 & 0 & 0.0 & & \\
\hline
\end{tabular}

Table 6: reveals that there is significant relation between Incontinence-related quality of life and items of sociodemographic characteristics (age, marital status, occupation, and source of income) while there were a highly significant relation between Incontinence-related quality of life and educational level of the studied sample. 


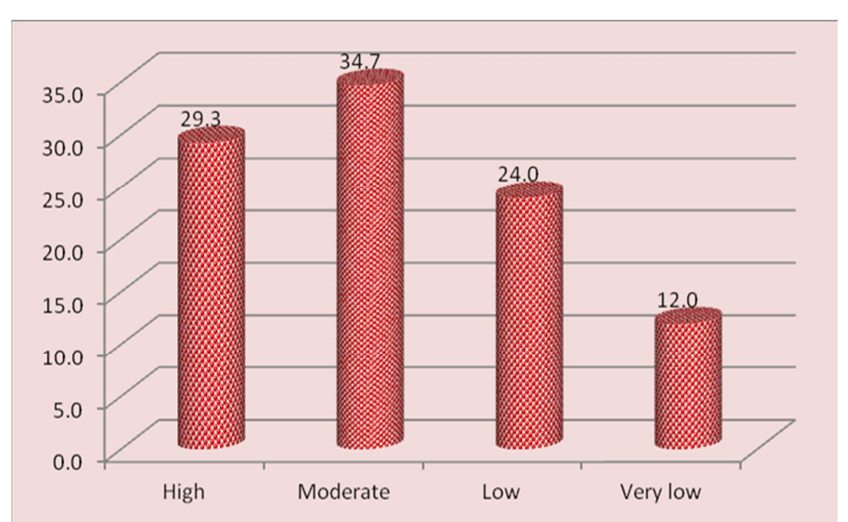

Figure 1. Frequency distribution of study sample regarding score ( $N=$ total self-esteem 75).

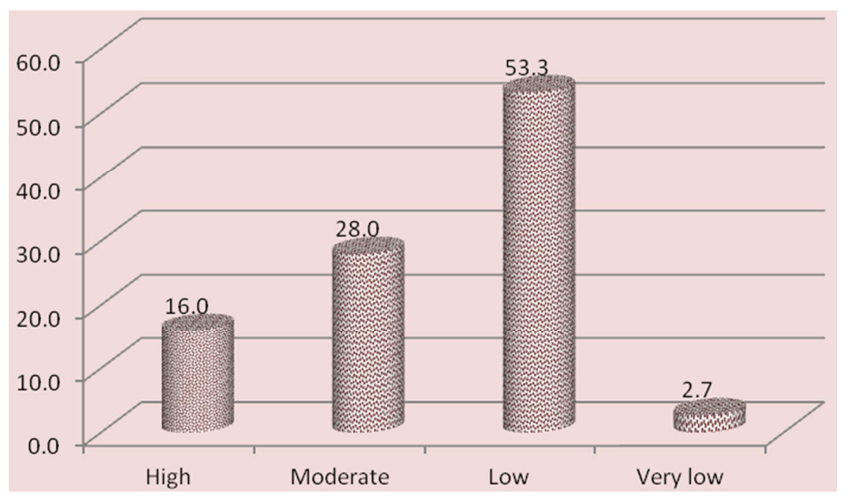

Figure 2. Frequency distribution of study sample regarding total Incontinence-Related Quality of Life score $(N=75)$.

\section{Discussion}

Urinary incontinence among postmenopausal women is a stigmatizing condition which causes difficulties in obtaining consistent epidemiological data. Perhaps because of stigma, this condition is associated with low rates of health care seeking. In spite of that, studies show that approximately $45 \%$ of post-menopausal women experience some involuntary urine loss [20].

In literature, there is a general agreement that UI have a negative impact on the quality of life, with implications on the psychological, social, physical and economic spheres, as well as on personal and professional relationships, and can even represent a motive of social isolation, low selfesteem, vulnerability to stress and depression. [21]. The current study aimed to determine the effect of urinary incontinence on quality of life and self esteem of postmenopausal women.

The results of the present study reveals that, more than half of study sample within age group $<50$ years old with a mean age $50.6 \pm 3.5$. This result is agreement with a study carried out by [22] who found that the average mean age of study sample was $50 \pm 7.23$ years. These results also in agree with [11] who founded in his study sample that the mean age of the women was 51 years old. This result inconsistent with a study carried by [23] who reported that their mean age of women in his study was $57.31 \pm 9.32$ years. Also this result inconsistent with [24] who founded that the mean age of participants was $70.17 \pm 6.5$ in this study.

Concerning to the marital status, the present study reveals that nearly three quarters of the total sample were married. This result consistent with a study carried by [25] who founded that a vast majority of the women were married. On other hand the result was inconsistent with a study carried by [26] who founded that majority of the patients having UI were widowed.

As regards to the educational level, the present study showed that about two thirds of the study samples have moderate educational level. This finding is incongruent with a study carried by [26] who founded that majority of the patients having UI illiterate. The result was disagreement with a study carried by [27] who founded that more than have of the sample are highly educated and teachers. Also, this goes in the same line with by [28] his result showed that more than three quarters of the sample have higher education. From view point of researcher theses differences in results may be due to differences in sample

The results of the present study regarding occupation proved that more than three quarters of the total sample was working. This result is incongruent with study carried by [29] that represented that more than three quarters of the patients were housewives. Also, this goes in the same line with [30] who stated that more than three quarters of women were housewives. Also this result is incongruent with result of [31] who founded that the majority of the study sample was unemployed. This difference may be due to culture in our community that believes that work is very important for women and help them to become more independent.

Concerning the number of delivery, the present study reveals that more than two thirds of the sample had 1-3 numbers of deliveries. This result is consistent with a study carried out by [32] who founded that more than two thirds of the sample had given birth to four children or more. As regards to the method of delivery the present study reveals that more than two thirds of the sample delivers normal. The result is in agreement with a study by [33] who stated that more than two thirds of the study sample had normal vaginal delivery. Also, the results of the present study revealed that the more than three quarters of the sample had no abortion.

The result of the present study illustrates that, more than half of the study sample had duration of urinary incontinence about 1 to less than 3 years. This result disagrees with a study carried out by [29] his result showed that less than half of the study sample had length of time with urinary incontinence about one year.

The result of the present study shows that, more than half of the study sample had doctor visit about 4-5 visits per year. The possible explanation from the researcher's point of view may be due to increase of the woman knowledge that helps her to understand the important of medical consultant visit for this problem. This may be due to reasons related to the most of sample were working women and also due to influence of UI on women household activities, social, sexual life and psychological status, so the woman seeking 
treatment was considering the symptoms as serious.

This result is inconsistent with [34] who stated that, The common reasons of women who consult professional help was afraid of urine's odour and shameful consequence in which offered healthcare services was assessed as appropriate. Furthermore, other reasons of seeking help were as follow: "the urine leakage has worsened, decreased physical activity, feel depressed because of urine leakage, have obtained information where to get help, have obtained information about what types of help are available, reduced amount of sleep, decreased general activity, too high costs for hygiene articles, decreased relationships with friends, social groups and etc., decreased sexual intercourse, tired of experiencing urine loss, asked about urine leakage when consulting a doctor, other health care professionals asked about urine leakage .

This result is in disagreement with [35], who stated that, despite the availability of numerous treatments which their effectiveness are well investigated worldwide, nearly half of community dwelling women living with UI do not seek professional treatment. Also, this goes in the same line with by [9] who stated that the stigma and embarrassment with UI may prevent woman from seeking treatment. Also [22] stated that most women don't consider UI as a health condition or they considered it as a natural process related to aging, having adapted to it in their daily lives, which could be explained by a lack of information this lead to that most woman haven't seek for treatment for UI. Also, most of them do not perceive the symptoms as indicators of a disease but they see them as a physiological consequence of pregnancies and childbirths or simply as a natural manifestation of ageing

The result of the present study illustrates that the more than three quarters of the study sample had urinary incontinence (last month) about $\geq 4$ times. Also about two thirds of the study sample had frequency urinary incontinence (day) 3-4 times. This result disagreement with a study carried out by [29] his result showed that less than one third of sample had urinary incontinence (last month) about 2-3 occurrences (per week), on other hand about one third of the sample had frequency urinary incontinence (day) 1-2 occurrences (per day) respectively. From view point of researcher this may explain the reasons of seeking professional help and attending the gynaecological units.

The result of the present study illustrates that, more than one third of the study sample had moderate self esteem. This result is consistent with [36] who stated that urinary incontinence starts gradually over time and increases often to the point of causing women to stop doing many of their normal activities, which cause wetness, odour, discomfort, and skin irritation; it can also damage self-esteem as a result of shame and embarrassment. Additionally the result was consistent with [37] who stated that the impact of UI on a woman's own emotional health is increasingly apparent. There are many studies showing the association between involuntary urine loss and indicators of psychological distress which can even represent a motive of social isolation, low self-esteem, social embarrassment vulnerability to stress and depression.

The result of the present study illustrates that about half the sample had low quality of life. The result was consistent with [20] his study showed that a considerable number of the respondents about two thirds reported poor QoL. Moreever, this goes in the same line by [38] who stated that the quality of life of women with UI is significantly lower than the quality of life of the women without UI. Also, result is consistent with [39] who stated that urinary incontinence have negative effects on women's quality of life, especially on the medical, physical, social, psychological, economical and sexual aspects.

The result of the present study is consistent with a previously mentioned study by [40] which highlighted that there is a link between women who have UI and lower (QoL). Also [41] who founded that the connection between UI and QoL identifying three problematic areas: daily life, recreational activities, and sex life. In addition, research has shown a decrease in social participation, physical health, emotional health, and lower scores on QoL measures [42] from view point of researcher this may be due to that UI cause bad odour for women and also get her clothes wet so this make her socially isolated and affect her physical and emotional health.

Additionally [43] reported that UI had impacts on social life ,psychological well-being, social interactions, activities, sexual and interpersonal relationships resulting in restrictions regarding going to public places, travelling, sleeping out and even visiting friends. Furthermore, incontinent women did not talk to anyone about their incontinence, not even with their husband, because they were ashamed of having the symptom and fear perception of urine odour [44].

The result of the present study illustrates that there was statistically significant correlation between total self esteem and total incontinence-related quality of life in the study sample. From view point of researcher this may be due to that UI may be a cause of great discomfort, shame, loss of self esteem and may cause sufferers to withdraw from social life, which in turn affect on the quality of life. Also the woman with high self esteem can engage in daily activities and become socially active so their quality of life increases than women with low self esteem.

This result consistent with [45] who stated that incontinent women are burdened with anxieties and feelings of embarrassment and shame and they live in constant fear that others will discover their condition. Women's sexual function and relationships with their partners are significantly affected by their incontinence, thus augmenting their feelings of low self-confidence. Furthermore, major depression has been shown to be more common in incontinent women, adding to the cycle of low self-esteem, increased social withdrawal and, ultimately, a reduction in quality of life.

The result of the present study illustrates that, there was statistically significant relation between total incontinencerelated quality of life and marital status of the study sample. from the researcher's point of view this may be due to that post-menopausal woman that are married a ware about 
importance of improving here quality of life because it's effect on the family And also she feels that she is responsible for her family and must respond to their needs so this may lead to increase her quality of life than non married women. This result disagreement with a study by [46] who founded that there wasn't significant differences between incontinence-related quality of life and marital status of the study sample. Also the result disagreement with a study by [47] his results did not confirm that the marital status of the surveyed women significantly influenced their quality of life.

The result of the present study showed that, there was statistically significant relation between total incontinencerelated quality of life and educational level. The possible explanation for this may be due to that education is critical to social development and has a profound impact on population quality of life and also education help women to learn how to deal with her problems and find various problem solving techniques that help her to improve quality of life. This result is consistent with a study carried by [30] who founded that education had significant association with the QOL postmenopausal woman. While, this result inconsistent with a study carried by [45] who founded that there isn't statistically significant relation between total incontinencerelated quality of life and educational level of the sample.

The result of the present study showed that, there is significant relation between total self esteem and age, marital status, occupation, and source of income of the study group. And there is a highly significant relation between total self esteem and educational level. from the researcher's point of view that employee woman and increase age with increase educational level make woman fell more experience and increase self confidence that have positive impact of woman self esteem.

\section{Conclusion}

In the light of present study, it could be concluded that Urinary incontinence were common in postmenopausal women who are a group that they need our special attention in terms of health related quality of life. UI with its associated symptoms can have a significant impact on the quality of life and a significant variety of perceptions and responses, often mediated by vulnerability to stress and decrease self esteem. Estimates may not accurately reflect the full scope of urinary incontinence as an embarrassment, and perceived stigmatization may cause women to be reluctant to communicate their concerns to physicians. The substantial psychosocial consequences of urinary incontinence stress the need for more public health and medical attention. UI symptoms directly affect HRQoL, which subsequently impacts negatively on mental well-being.

\section{Recommendations}

Based on the findings of the current study, the following recommendations are suggested:

(1) Continuous assessment for all QOL domains for incontinent women should be a part of the nursing care

(2) Media orientation and educational programs for women about the risk factors of urinary incontinence should be provided.

(3) Constructing a strategy by ministry of health to identify menopausal women with the risk factors of urinary incontinence to maintain their health by preventing, treating and coping.

(4) Further research is required to improve our understanding of psychological and economic impact of this condition.

\section{References}

[1] Melville, JL., Walker, E., Katon, W., et al (2017): Prevalence of co-morbid psychiatric illness and its impact on symptom perception, quality of life, and functional status in women with urinary incontinence. Am J Obstet Gynecol.187:80-7.

[2] Stewart, WF., Rooyen, JB., Cundiff, GW., Abrams, P., Herzog, AR., Corey, R., et al. (2017): prevalence and burden of overactive bladder in the United States. World J Urol; 20:327-36.

[3] North American Menopause Society, (2015): Hormone therapy and menopause FAQ's Accessed 1/16/2015.

[4] Landi, F., Cesari, M., Russo, A., Onder, G., Lattanzio, F., Bernabei, R., et al. (2015): Potentially reversible risk factors and urinary incontinence in frail older people living in the community. Age and Ageing; 32(2): 194-9.

[5] Hsieh, CH., Su, TH., Chang, ST., Lin, SH., Lee, MC., \& Lee, MY. (2017): Prevalence of and attitude toward urinary incontinence in postmenopausal women. International J Gynecol Obstet;100, (2):171-4.

[6] Samreen, K., Athar, A., Shaista, M., et al. (2017): The influence of menopause on urinary incontinence in the women of the community: a cross-sectional study from North India. International Journal of Reproduction, Contraception, Obstetrics and Gynecology. Mar; 6(3):911-918.

[7] Perera, J., Kirthinanda, DS., Wijeratne, S., \& Wickramarachchi, TK. ( 2014): Descriptive cross-sectional study on prevalence, perceptions, predisposing factors and health seeking behaviour of women with stress urinary incontinence. BMC Women`s Health.;14:78.

[8] Jameel, S., \& Mahmud, SN. (2016): Frequency of different risk factors associated with recurrent urinary tract infection among postmenopausal women. J Ayub Med Coll Abbottabad; 28(2):353-6. 1.

[9] Abrams, P., Andrew, P., \& Nikki, C. (2015): The impact of urinary incontinence on health-related quality of life (HRQoL) in a real-world population of women aged 45-60 years: results from a survey in France, Germany, the UK and the USA . BJU Int; 115: 143-152.

[10] Rett, MT., Giraldo, PC., Gonçalves, AK., Eleutério Junior, J., Morais, SS., DeSantana, JM., \& Amaral., RL. (2014) : Shortterm physical therapy treatment for female urinary incontinence: a quality of life evaluation. Urol Int; 93 (1): 235-9. 
[11] Mariana, TR., Érica, B W., Josimari, M., De., et al. (2016): Female urinary incontinence: quality of life comparison on reproductive age and postmenopausal period. Fisioter Mov. Jan/Mar; 29(1):71-8.

[12] Eunok, P., \& Kyungja., K. (2014): Incontinence-Quality of Life (I-QOL) among women with urinary incontinence. Advanced Science and Technology Letters Vol.72 (Healthcare and Nursing) pp.77-80.

[13] Park, K E., Kwon, MH., \& Kwon, Y E. (2013): Correlation among depression, death. anxiety, and quality of life of aged women. Journal of Korean Public Health Nursing, 27(3), 527538 .

[14] Jolleys, JV. (2017): Reported prevalence of urinary incontinence in women in a general practice. Br Med J (Clin Res Ed);296:1300.

[15] -Tso, C., DNP, FNP-BC, CRP, \& Lee, W. (2018): Postmenopausal women and urinary incontinence. American nursing today. Vol. 13 No. 1.

[16] Chiarapa, TR., Cacho, DP., \& Alves, AF. (2016): Avaliação cinético funcional: Incontinência urinária feminina: Assistênciafisioterapêutica e multidisciplinar. São Paulo: Livraria Médica Paulista.Paula Nelas et al. / Procedia - Social and Behavioral Sciences 217. 1118-1123.

[17] Hayder \& Schnepp, et al. (2010): An international urogynecological association (IUGA)/international continence society. (ICS) joint report on the terminology for female pelvic floor dysfunction. Neurourology. and Urodynamics 29(1): 4-20.

[18] Patrick, DL., Khalaf, KM., Dmochowski, R., Kowalski, JW., \& Globe, DR. (2013): Psychometric performance of the Incontinence Quality-of-Life Questionnaire among patients with overactive bladder and urinary incontinence. Clinical Therapeutics, 35(6), 836-845.

[19] Patrick, DL., Baverndam, TG., Martin, ML., Buesching, DP. (1996): Quality of life of persons with urinary incontinence: development of a new measure. Adult Urol 47:67-72.

[20] Abiola, O., Ogunlaja, O., Idowu, A., \& Ayeni, S. (2016): Prevalence, quality of life assessment of urinary incontinence using a validated tool (ICIQ-UI SF) and bother someness of symptoms among rural community: dwelling women in Southwest, Nigeria. Int J Community Med Public Health;3(5): 989-997.

[21] Saboia, D., Firmiano, M., Bezerra, K., Neto, J., Oriá, M., \& Vasconcelos, C. (2017): Impact of urinary incontinence types on women's quality of life. Rev. esc. enferm. USP vol.51 São Paulo.

[22] Nelasa, P., Duartea, J., Diasa, A., Chavesa, C., Coutinhoa, E., \& Amarala, O. (2016): Vulnerability to stress and quality of life of women with urinary incontinence. Procedia - Social and Behavioral Sciences, 217, 1118-1123.

[23] Mohammed, S., Karmallawy, E., \& Mohamed, R. (2015): Assessing quality of Life of women with urinary incontinence. Egyptian nursing journal.

[24] Morowatisharifabad, M., Rezaeipandari, H., Mazyaki, A., \& Bandak, Z. (2015): Prevalence of Urinary Incontinence among Elderly Women in Yazd, Iran: A Population-Based Study. Elderly Health Journal; 1(1): 27-31.

[25] Wieder-Huszla, S., Szkup, M., Jurczak, A., Samochowiec, A.,
Samochowiec, J., Stanisławska, M., Karakiewicz, B., \& Grochans, E. (2014): Effects of socio-demographic, personality and medical factors on quality of life of postmenopausal women. Int J Environ Res Public Health, 11(7): 6692-6708.

[26] Khan, S., Ansari, M., \& Mohsin, Z. (2017): The influence of menopause on urinary incontinence in the women of the community: a cross-sectional study from North India. International Journal of Reproduction, Contraception, Obstetrics and Gynecology; 6(3):911-918.

[27] Orabi, E. (2017): Effect of health education intervention on knowledge, and attitude regarding menopausal period among premenopausal female employees. The Egyptian Journal of Community Medicine, Vol. 35 No. 3. 71-84.

[28] Marcin, Z., Daria. K., Maria, M., Daria, P., Marcin, O., \& Irena, M. ( 2017): The impact of pelvic floor exercises on the quality of life of women with urinary incontinence - Analysis of pregnancy and the Postpartum Period. J Nov Physiother Phys Rehabil 4(2): 035-041.

[29] Nojomi, M., Moradi-Lakeh, M., \& Baharvand, P. (2009): Incontinence quality of life questionnaire (IQOL): Translation and validation study of the Iranian version. Int Urogynecol J, 20:575-579.

[30] Charandabi, S., Rezaei, N., Hakimi, S., Montazeri, A., Taheri, S., Taghinejad, H., \& Sayehmiri, K. (2015): Quality of life of postmenopausal women and their Spouses: A communitybased study. Iran Red Crescent Med J; 17(3): e21599.

[31] Shohani, M., Carson, K., Sayehmiri, K., \& Shohani, F. (2015): Effective Factors on Urinary Incontinence in Natural Menopausal Women. Thrita, 4(4): e29754.

[32] Ghodsbin, F., Kargar, M., Jahanbin, I., \& Sagheb, MM. (2012): The efficiency of a behavioral intervention program for urinary incontinence in elderly females. J Nurs Care 1:122.

[33] Pakgohar, M. (2015): Factors associated with postmenopausal women's decisions to seek treatment for urinary incontinence. Elderly Health Journal; 1(2): 42-45.

[34] Bradway, C., \& Strumpf, N. (2009): Seeking care: women's narratives concerning long-term urinary incontinence. Urologic Nursing; 28(2): 123-9.

[35] El-mowafy, R., El-Ezaby, H., \& O Elalem, O. (2015): Prevalence of urinary incontinence among middle age women and associated risk factors in Port-Said City. A valiable at elmagla.egy2010@yahoo.com.

[36] Botlero, R., Robin, B., Urquhart, DM., \& Davis, SR. (2010): Urinary incontinence is associated with lower psychological general well-being in community dwelling women. Menopause 17: 1-6.

[37] Baci, E., Gurlevik, O., Gun, İ., \& Gunay, O. (2012): The effects of stress urinary incontinence on the quality of life of Turkish women in the reproductive age group. Turk J Med Sci; 42 (5): 845-851.

[38] Bilgic, D., \& Beji., NK. (2010): Lower urinary tract symptoms in women and quality of life. International Journal of Urological Nursing, November; 4.Issue105.

[39] Perez-Lopez, FR., Cuadros, JL., Fernandez-Alonso, AM, et al. (2012): Urinary incontinence, related factors and menopauserelated QoL assessed with Cervantes Scale. Maturitas 73(4): 369-372. 
[40] Riss, P., \& Kargl, J. (2011): Quality of life and urinary incontinence in women. Maturitas 68: 137-142.

[41] Aguilar-Navarro, S., Navarrete-Reyes, AP., Grados- Chavarria, BH., et al. (2012): The severity of urinary incontinence decreases health related QoL among community dwelling elderly. Journal of Gerontology, 67(11): 1266-1271.

[42] Ünsal, A., Tözün, M., \& Arslantaş, D. (2013): Urinary Incontinence, Related Factors and Depression among 20 Aged and Over Women in Beylikova District Centre in Eskișehir, Scope Med, 12(3): 232.

[43] Hung, WY., Chan, WY., Cheon, CW., Tong, AW., Wong, T. \& YIP, SK. (2010): Postnatal Urinary Incontinence after Caesarean Section, Hong Kong J Gynaecol Obstet Midwifery, 10:58.

[44] Sinclair, A., \& Mrcog, I. (2011): The psychosocial impact of urinary incontinence in women. The Obstetrician \& Gynaecologist. Volume 13, Issue 3. pp. 143-148.

[45] Pereira, M., Lynch, B., Hall-Faul, M., \& Pedras, S. (2016): Quality of life of women with urinary incontinence in rehabilitation treatment. Journal of Health Psychology, 1-10.

[46] Wieder-Huszla, S., Szkup M., Jurczak, A., Samochowiec, A., Samochowiec, J., Stanisławska M., Rotter I., Karakiewicz B., \& Grochans, E. (2014): Effects of socio-demographic, personality and medical factors on quality of life of postmenopausal women. Int. J. Environ. Res. Public Health;11:6692-6708.

[47] Borges, JB., Neri, L., Sigrist, RM., Martins, LO., Guarisi, T., \& Marchesini , AC. (2009): Assessing quality of life of women with urinary incontinence using the Kings Health Questionnaire, Einstein, 7, p 305. 